\title{
SER COMO VESTIGIO. ACERCA DEL ORIGEN ONTOLÓGICO DE LO HISTÓRICO-MUNDANO EN \\ HEIDEGGER
}

\section{BEING AS VESTIGE. ON THE ONTOLOGICAL ORIGIN OF THE WORLD-HISTORICAL BY HEIDEGGER}

\author{
Carlos Di Silvestre \\ Departamento de Filosofía \\ Universidad Nacional de Cuyo, Argentina
}

RESUMEN: El artículo examina una cuestión central en la interpretación existencial de la historicidad del Dasein: la destrucción fenomenológica de la comprensión usual de «lo histórico» como algo que pertenece al pasado. En este marco, discute la tesis heideggeriana de que el carácter histórico de lo intramundano no se debe a su pertenencia al tiempo pasado, sino que se origina ontológicamente en su procedencia de un mundo sido. A partir del análisis de la distinción entre lo pasado y lo sido como determinaciones temporales y de la resolución como modo de ser histórico del Dasein, el artículo procura mostrar que la estructura ontológica de lo histórico-mundano consiste en ser el vestigio de posibilidades de existencia.

\section{Palabras Clave: Heidegger, historicidad, pasado, resolución, vestigio}

ABSTRACT: This article examines a central issue of the existential interpretation of the historicity of Dasein: the phenomenological destruction of the usual comprehension of «the historical» as belonging to the past. In this framework, it discusses the Heideggerian thesis according to which the historical character of the intraworldly does not depend on past time but originates ontologically from a world that has been. Beginning with the distinction between past and «been» as two temporal determinations and with resoluteness as a mode of historical being of Dasein, the article attempts to show that the ontological structure of the world-historical consists of being the vestige of the possibilities of existence.

KEYWORDS: Heidegger, historicity, past, resoluteness, vestige 
Como resultado de una renovada concepción del tiempo como temporeidad del Dasein y de una fructífera confrontación crítica con Wilhelm Dilthey y Paul Yorck, Heidegger lleva a cabo, en el marco de la Ontología existencial, una interpretación de la historicidad en cuanto modo fundamental de ser del Dasein. Desde el punto de vista metódico, la interpretación de la historicidad presenta dos momentos diferenciados y articulados: a) la destrucción fenomenológica de la comprensión «vulgar» de la historia, que prepara el terreno para b) la construcción o proyección existencial del ser histórico del Dasein a partir de la temporeidad. En el contexto de la destrucción, tanto en Ser y tiempo como en textos posteriores, Heidegger plantea la pregunta de por qué determinados entes, acontecimientos o situaciones pueden ser considerados como históricos. Esta pregunta tiene un sentido ontológico, pues interroga por el carácter histórico en cuanto estructura de ser de lo intramundano y por el origen de esa estructura de ser.

En el siguiente estudio examinaremos, en primer lugar, la respuesta de Heidegger a la pregunta mencionada: el carácter histórico de lo intramundano no se debe a su pertenencia al pasado sino que se funda primariamente en su procedencia de un mundo sido. Consideraremos además las objeciones críticas que esta respuesta ha suscitado. En segundo lugar, dichas objeciones nos conducirán al análisis de la distinción entre lo pasado y lo sido y de la resolución como modo de ser histórico del Dasein. A partir de estos análisis, intentaremos finalmente explicitar la interpretación heideggeriana mediante la tesis de que lo intramundano procede de un mundo sido y, por ende, puede ser considerado como histórico-mundano, en la medida en que se muestra como vestigio, es decir, como huella y testimonio de una posibilidad de existencia.

\section{La interpretación usual de la historia}

Heidegger denomina interpretación vulgar ${ }^{1}$ a la comprensión inmediata y regular del Dasein, que se expresa de una u otra manera acerca del «mundo». El

\footnotetext{
${ }^{1}$ El término «vulgar» no tiene en este caso un sentido negativo, sino que recoge el significado del adverbio latino vulgo: «comúnmente», «por todos», «de ordinario». Pero puesto que dicho término ha adquirido una connotación en cierto modo peyorativa, utilizaremos en su lugar el término «usual».
} 
primer paso de la destrucción de la interpretación usual de la historia consiste entonces en delimitar la comprensión inmediata de lo histórico tomando como punto de partida el modo como el Dasein se expresa regularmente acerca de ello, el modo como tal comprensión ha quedado fijada en lo que se dice, en el plano de la articulación lingüística. El segundo paso consiste en una deconstrucción crítica de los diversos conceptos en los que quedó documentada la interpretación usual de la historia. Ahora bien, la deconstrucción de una interpretación usual no conduce a una «demostración» de la presunta falsedad de dicha interpretación, sino que más bien procura descubrir, a través de lo comprendido inmediatamente, en este caso, como «historia», «aquello que es originariamente histórico» $(S Z, 378)^{2}$.

Heidegger observa que el término «historia» se presenta siempre con una ambigüedad característica, pues se refiere tanto a la "realidad histórica» ( $S Z$, 378), a las res gestae, cuanto al posible saber acerca de ella, a la historia en el sentido de historia rerum gestarum. ${ }^{3}$ En relación con la interpretación usual de la historia en el sentido de realidad histórica, de ente histórico, Heidegger identifica en $S Z$ cuatro significados distintos, que examinaremos a continuación a fin de ganar una primera orientación para la discusión hermenéuticocrítica posterior.

1) Tiene un uso preferente aquel significado de «historia» en virtud del cual se comprende el ente histórico como algo pasado [Vergangenes]. En este sentido, el adjetivo "pasado» puede atribuirse: a) a un ente que ya no es real, efectivo, que desapareció o fue destruido; b) a un ente que, si bien todavía existe efectivamente,

${ }^{2}$ Las obras citadas de Heidegger se indican entre paréntesis en el cuerpo del texto mediante la abreviatura correspondiente seguida del número de página. Las referencias bibliográficas completas de las obras a las que remiten las abreviaturas aparecen al final en la Bibliografía. En todos los casos, las traducciones son nuestras.

${ }^{3}$ En castellano se utiliza habitualmente la misma palabra, «historia», para referirse a ambos significados del término, aunque también se habla de "historiografía» para referirse al saber histórico. En cambio, en alemán pueden utilizarse dos palabras distintas: Geschichte y Historie. Por lo general, se utiliza Geschichte para nombrar la realidad histórica, mientras que con Historie se nombra siempre el saber histórico, la ciencia histórica, la Geschichtswissenschaft. Ambas palabras tienen raíces distintas: Geschichte procede del verbo alemán geschehen: «acontecer», «suceder», «ocurrir». Historie, lat. historia, procede de la voz griega historia: «informe», «noticia», «relato», «narración». La distinción es relevante para nuestro tema, pues, como veremos, Heidegger procura determinar el ser histórico [geschichtlich sein] precisamente a partir del sentido del verbo geschehen. 
no tiene sin embargo «eficacia» o «repercusión» [Wirkung] sobre el presente, sobre el «hoy», por ejemplo, a las antigüedades que se conservan en los museos; c) a un ente o a un estado de cosas, a los «acontecimientos de entonces [damalige Ereignisse]» $(S Z, 378)$, que, aunque pasados, siguen actuando de algún modo sobre el hoy. El sentido básico de lo histórico como pasado apunta pues al ente en cuanto aquello que nos precedió y quedó atrás, que «pertenece irrevocablemente al tiempo anterior» $(S Z, 378)$.

2) El término «historia» puede referirse también al pasado [Vergangenheit] del ente, pero no en el sentido de que nos precedió y quedó atrás, sino de que tiene su origen en el pasado y se extiende en el tiempo. Así se habla, por ejemplo, de «desarrollo histórico» de una nación o de «historia evolutiva de los mamíferos». En efecto, en este sentido amplio la vida animal y vegetal tiene una historia milenaria y llena de cambios, de la cual los fósiles dan testimonio suficiente. Y no sólo la vida sino también la Tierra, el globo terráqueo, tiene su propia historia, testimoniada en las grandes transformaciones de la corteza terrestre. En la comprensión que está a la base de este significado de «historia» se tiene pues a la vista siempre sucesos que ocurren en el tiempo, que se siguen unos de otros y repercuten unos en otros y que ocupan un cierto espacio temporal. Estos sucesos pasan con el paso del tiempo, es decir, ingresan en el pasado y pertenecen a la historia en la medida en que ingresan en el pasado. "Historia significa aquí un «encadenamiento de sucesos y de efectos» que se extiende a lo largo de "pasado", «presente» $\mathrm{y}$ «futuro»» (SZ, 378-379). En esta comprensión de la historia es indiferente en qué ámbito óntico tiene lugar la respectiva serie de acontecimientos.

3) A diferencia del significado anterior, «historia» se utiliza también como término para designar una región determinada del ente: «las transformaciones y vicisitudes de los hombres, de las agrupaciones humanas y de la «cultura»» ( $S Z$, 379). «Historia» designa en este caso el conjunto o la serie de los acontecimientos y productos humanos en cuanto ámbito óntico. Este uso más bien teorético del término surge a partir de la determinación (moderna) de la existencia humana a través del «espíritu» y la «cultura». Y, sobre su base, es habitual la distinción y oposición de la historia frente a la naturaleza, comprendida también en sentido óntico-regional.

4) $Y$, finalmente, se comprende también como histórico a «lo transmitido [das Überlieferte] en cuanto tal» $(S Z, 379)$, es decir, a lo que ha llegado desde el 
pasado hasta el presente mediante algún tipo de transmisión comunicativa. Esta transmisión puede ser explícita, por ejemplo, a través del relato histórico o de la ciencia histórica, de manera que se reconoce lo transmitido en cuanto tal, o puede ser simplemente implícita, de manera que lo transmitido, oculto en su procedencia, es recibido o aceptado como algo obvio que simplemente sale al encuentro desde el mundo circundante y compartido.

\section{El problema del origen ontológico de lo histórico-mundano}

En primer lugar nos referiremos a la discusión crítico-deconstructiva en torno al primer significado usual de la «historia», a la comprensión habitual del ente histórico como algo pasado, como lo que pertenece a un tiempo anterior. Como ejemplo de ente histórico mencionamos a las antigüedades que se conservan en los museos o incluso en las propias casas. Piénsese por ejemplo en un antiguo reloj de pared heredado de algún familiar o antepasado. Este tipo de ente presenta una característica duplicidad desde el punto de vista de su sentido tempóreo, pues, por un lado, tales entes son considerados como algo pasado y, por otro lado, están todavía ahí, están efectivamente presentes. En vista de ello, Heidegger pregunta de dónde procede el carácter histórico de los útiles conservados, si ellos están todavía presentes. En efecto, si el carácter histórico de tales entes se funda en su pertenencia al pasado, ¿qué es lo propiamente pasado en los útiles históricos que aún se conservan? Su carácter histórico no puede fundarse en el hecho de que sean «objeto de interés historiográfico» $(S Z, 380)$, ni tampoco en el hecho de que ya no sean usados. Por el contrario, para que sea posible un determinado interés histórico-científico, la cosa en cuestión tiene que ser ya «en sí misma de alguna manera histórica» $(S Z, 380)$. Pues si el historiador no la considerara de antemano como histórica, ciertamente no podría verla como posible objeto de su investigación. Por otra parte, tampoco la circunstancia de que un útil histórico esté fuera de uso es una condición necesaria para la constitución de su carácter histórico, pues es posible que el útil siga siendo usado, como puede ser el caso del antiguo reloj heredado que se conserva en la propia casa. La tesis de Heidegger acerca del origen del carácter histórico de los entes históricos es entonces la siguiente:

En uso o fuera de uso, ellos [los útiles históricos] sin embargo no son ya lo que eran. ¿Qué es lo "pasado" [en ellos]? No otra cosa que el mundo, dentro del cual ellos, pertenecientes a un contexto de útiles, comparecían como 
a la mano y eran usados por un Dasein que, siendo-en-el-mundo, se ocupaba de ellos. Es el mundo lo que ya no es $(S Z, 380)$.

Heidegger ve que el mero hecho de que un útil conservado pertenezca al pasado en el sentido habitual del «tiempo anterior», del «ahora que ya no es», no puede conferirle carácter histórico, pues dicho útil está todavía ahí, pertenece de algún modo también al presente. Por ello concluye que el carácter histórico de tales útiles se funda más bien en su pertenencia a un mundo "pasado", que "ya no es», dentro del cual comparecían como a la mano y eran usados por el Dasein. Es claro que esta tesis exige, a su vez, la aclaración del sentido en que el mundo puede ser considerado como pasado. Pues la tesis no implicaría un avance en la argumentación y se tornaría superflua si en ella el «mundo que ya no es» fuese comprendido también como algo pasado en el sentido de lo que ahora ya no está presente. En este caso el concepto de mundo tiene un sentido ontológico-existencial, es decir, el mundo es comprendido como un fenómeno que pertenece a la estructura de ser del Dasein. Por ello, Heidegger aclara su tesis y la reformula en términos del carácter de sido del mundo:

Las antigüedades que todavía están ahí tienen carácter de "pasado», carácter histórico, sobre la base de su pertenencia, en cuanto útiles, y de su procedencia [Herkunft] de un mundo sido [gewesene Welt $]$ de un Dasein que ha ex-sistido [da-gewesenes Dasein] (SZ, 380-381).

Las antigüedades conservadas en los museos, los entes históricos en general, tienen carácter histórico en virtud de su pertenencia a y procedencia de un mundo sido y no pasado. La distinción es relevante. El Dasein nunca puede tener, en cuanto Dasein, carácter de pasado en el sentido de algo que ahora ya no está efectivamente presente. Pues en razón de su modo de ser, nunca está presente o ya no está presente. Que el Dasein es, significa ontológicamente que existe. Por ello, que el Dasein ya no es, no significa, en un sentido ontológico estricto, que sea algo pasado, sino sólo que ha existido. Y lo mismo sucede con el mundo, en la medida en que, en cuanto significatividad, forma parte de la estructura de ser del Dasein ${ }^{4}$. En sentido ontológico, un mundo perteneciente a un Dasein que ha existido no ha pasado, sino que ha sido.

\footnotetext{
${ }^{4}$ Cf. $S Z \$ 18$.
} 
Puesto que el carácter histórico de los entes intramundanos se funda ontológicamente en el haber sido del mundo de un Dasein, Heidegger concluye que el ser del Dasein es lo primariamente histórico. Esto implica que todo lo intramundano, ya sean entes «culturales» en el sentido más amplio, la naturaleza del mundo circundante en cuanto "suelo de la historia» $(S Z, 381)$ e incluso los propios acontecimientos humanos, debe ser considerado por su parte como secundariamente histórico. Para referirse a lo intramundano, cuyo carácter histórico se funda en su procedencia de un mundo sido, Heidegger utiliza terminológicamente la expresión «lo histórico-mundano [das Welt-geschichtliche]» $(S Z, 381)$.

El recurso heideggeriano al haber sido del mundo y del Dasein como vía para mostrar el origen ontológico de lo histórico-mundano deja, según piensa Günter Figal, el problema de fondo sin resolver ${ }^{5}$. Pues la interpretación heideggeriana no permite ver de qué modo un útil histórico determinado, por ejemplo, el sable de José de San Martín, pueda distinguirse de un arma no histórica cualquiera. Aclarar el carácter histórico del útil significa, señala Figal, «decir más exactamente en qué sentido los objetos históricos mismos ya no son, incluso en el caso de que ellos sean aún usados, "lo que eran” ". Según Figal, el útil histórico no es significativo sólo en el sentido en que es significativo lo no histórico: un útil histórico como el sable de San Martín tiene, por así decirlo, cierto plus de significación, que le da una relevancia determinada dentro del mundo. Esta relevancia significativa de lo histórico se manifiesta, se hace comprensible, también de un modo destacado: en la medida en que se sabe que tal útil histórico fue significativo también para otros y cómo lo fue. Esto sólo se puede saber si se conocen los correspondientes enunciados históricos sobre ese útil. Incluso cuando sea aún usado, un útil histórico es, afirma Figal, aquel que siempre es objeto de enunciados históricos y éstos, a su vez, son enunciados datados sobre determinados comportamientos del Dasein. Así, mediante enunciados datados de la forma «entonces, cuando tal o cual cosa era usada por X o pertenecía a X», se sabe, por ejemplo, que el reloj de pared heredado fue usado en un determinado tiempo anterior por un antepasado. Los enunciados históricos, que ciertamente no se limitan a objetos del tipo men-

\footnotetext{
${ }^{5}$ Cf. G. Figal (2000), pp. 314-316.

${ }^{6}$ Figal (2000), p. 315.
} 
cionado ni a comportamientos característicos de la ocupación cotidiana, son pues aquello que confiere a lo intramundano ese plus de significación, esa particular relevancia en que consiste su carácter histórico. El carácter histórico del ente intramundano (e incluso de los comportamientos del Dasein) se origina entonces, según Figal, en la transmisión de enunciados históricos de la forma mencionada ${ }^{7}$.

En principio, es necesario reconocer que la tesis de Figal precisa y complementa el sentido de la tesis heideggeriana acerca del origen del carácter histórico de lo intramundano. Pues la procedencia y la pertenencia de lo histórico-mundano a un mundo sido sólo pueden ser efectivamente accesibles a través de enunciados históricos datados, que, sobre la base de su fijación en la expresión lingüística, pueden ser comunicados y transmitidos por las sucesivas generaciones hasta alcanzar el presente respectivo. Heidegger mismo ha considerado en cierto modo este fenómeno de la transmisión en el ámbito de la historia mediante la explicitación del significado 4 de «historia».

Sin embargo, el hecho de que el carácter histórico de lo intramundano sea accesible habitualmente a través de enunciados históricos, no implica la conclusión, de tipo ontológico, de que el carácter histórico en cuanto estructura de ser se constituya mediante la transmisión de enunciados datados. Cuando Figal distingue entre el ente histórico y el no histórico e intenta mostrar el origen del primero en el sentido de su relevancia significativa dentro del mundo, sin duda apunta a un fenómeno auténtico y que incluso requiere de una explicación suficiente en el marco de una reflexión de principio acerca de la historia. Pero con ello no se refiere al problema suscitado por Heidegger. En efecto, si se parte de las premisas planteadas por Heidegger, la distinción entre ente histórico y no histórico no puede ser aceptada, pues todo ente intramundano, en la medida en que pertenece a un mundo sido, es siempre ya un

${ }^{7}$ Cf. Figal (2000), p. 316: «El relato de «historias» es necesario para que la cadena de los modos de comportamiento y de los entes que comparecen en ellos pueda ser transmitida y nuevamente también parcialmente inventada. El «acontecer», que, según Heidegger, caracteriza la historia, no es otra cosa que la siempre ya realizada transmisión [Überlieferung] de cadenas de comportamiento, que, si se prescinde del escrito histórico y del género de la novela histórica, no tiene autor determinado ni puede ser denegado como tal a nadie: a uno le «ocurre» estar en una transmisión o tradición de cadenas de comportamiento». 
ente histórico-mundano. "Con la existencia del ser-en-el-mundo histórico, lo a la mano y lo que está ahí se encuentran incorporados desde siempre a la historia del mundo» $(S Z, 328)$.

Los enunciados datados de la forma "entonces, cuando..." narran y muestran el específico modo en que lo intramundano es histórico y, en cuanto tales, pueden tener además la función de destacar la relevancia significativa de un ente vinculado con alguna acción humana que deba ser transmitida y recordada. Por ello, pueden ser considerados como la ratio cognoscendi de lo histórico-mundano. Pero la formulación de enunciados históricos acerca de un ente o de algún acontecimiento sólo es posible sobre la base de su previo acontecer o ingreso en el mundo y, por ende, a partir de su pertenencia a y procedencia de un mundo sido, lo cual tiene que ser considerado entonces como la ratio essendi del carácter histórico de lo intramundano

La objeción de Figal nos ha permitido ver que la tesis heideggeriana ha dejado sin aclarar cómo puede lo intramundano proceder de un mundo sido y, por ende, ser considerado posteriormente como histórico-mundano. Pues si el carácter histórico de lo intramundano se origina en una Herkunft, en una procedencia, que no tiene lugar primariamente mediante la transmisión de enunciados datados, cabe preguntar en qué sentido habla Heidegger de procedencia en este contexto. Es claro que la respuesta a esta pregunta se vincula con la necesidad de aclarar también en qué consiste propiamente el carácter histórico en cuanto estructura ontológica de lo intramundano. A continuación nos ocuparemos en esta cuestión.

\section{La distinción entre lo pasado y lo sido}

Sobre la base de la deconstrucción de la interpretación de la «historia» realizada en $S Z$, Heidegger retoma y profundiza dicha problemática en una lección de 1934, publicada con el título de Logik als die Frage nach dem Wesen der Sprache ${ }^{8}$. En este texto la discusión hermenéutica se centra fundamentalmente

\footnotetext{
${ }^{8}$ Esta lección es un texto de importancia para nuestro tema, pues representa uno de los pocos documentos, que datan del período posterior a $S Z$, donde Heidegger retoma y reformula de un modo relativamente amplio su concepción de la historicidad a partir del campo conceptual y la
} 
en el significado usual 2. De acuerdo con este significado, la historia consiste en una serie de sucesos que se extienden en el tiempo y que, en cuanto tales, ingresan en el pasado. A partir de esta comprensión de la historia se habla, por ejemplo, de «historia del capitalismo» con la misma legitimidad con la que se habla también de «historia natural de las plantas». En GA 38 Heidegger opone a esta comprensión amplia y oscilante de la historia, que se expresa en el mencionado uso lingüístico, la tesis de que la "historia es lo que distingue el ser del hombre» $(G A 38,81)$. Esta tesis retoma el presupuesto básico del que parte la interpretación heideggeriana en $S Z$ : el Dasein es el único ente histórico, el ser histórico es lo que distingue su ser. En cambio, en el significado 2 lo aprehendido bajo el término «historia» es tan amplio que con ello se mienta cualquier tipo de modificación o cambio: coincide con el concepto más general de movimiento. Frente a ello, Heidegger distingue tres tipos de movimiento: el mero desarrollo o transcurso [Ablauf] de un suceso mecánico, que se da ya en el nivel de lo inorgánico, de «la Tierra»; el proceso [Vorgang], que se da sólo en la esfera de la vida, y el acontecer [Geschehen], que constituye el movimiento o movilidad exclusiva del ser del hombre ${ }^{9}$. De acuerdo con esta distinción, no hay historia en cualquier serie de sucesos que implica algún cambio, sino sólo allí donde está en juego el ser del hombre en cuanto acontecer.

La distinción que Heidegger propone no tiene la finalidad de establecer una demarcación estricta entre ámbitos ónticos distintos. Antes bien, busca poner de relieve el sentido ontológico de la historia mediante la identificación del acontecer como modo de ser del Dasein. En todo caso, la distinción está contenida y complementa el resultado fundamental de la destrucción en $S Z$ : el ser del Dasein es lo primaria u originariamente histórico en la medida en que sólo su ser consiste en un acontecer. Pero la distinción no implica una negación del posible carácter histórico del ente no humano, de la Tierra o de la vida. Las alteraciones físico-químicas de un ente inorgánico o los procesos vitales de un ente orgánico en cuanto formas de movimiento no tienen en sí mismos carácter histórico. Sin

perspectiva temática propios de la Ontología existencial. Por otro parte, GA 38 es un importante documento también desde el punto de vista de los estudios biográficos sobre Heidegger, pues permite una comprensión más amplia de la situación de Heidegger en la Universidad poco tiempo después de su renuncia al rectorado. Para una ilustración acerca de las circunstancias históricas en las que surge $G A 38$, véase Rüdiger Safranski (1994).

${ }^{9}$ Cf. GA 38, 88-89. 
embargo, estas formas de movimiento, estos cambios, pueden convertirse también en acontecimientos históricos en el caso de que sean descubiertos y se tornen significativos para el Dasein. Así, por ejemplo, un movimiento telúrico de gran intensidad no es en sí mismo histórico en cuanto suceso natural, pero puede convertirse también en un acontecimiento histórico si es vivido por el Dasein como una catástrofe natural, es decir, si produce alarma y destrucción en el mundo circundante y compartido de una comunidad humana. A esta posibilidad Heidegger la ha caracterizado como el «»acontecer» intramundano» $(S Z, 389)$ del mero ente real, en virtud del cual éste se convierte en un ente histórico-mundano. Aquí se aprecia claramente que el posible carácter histórico del ente intramundano se origina ontológicamente en el ser histórico del Dasein.

Un segundo aspecto relevante de la destrucción de la "historia» en $S Z$ que Heidegger retoma y precisa en $G A 38$ es el referido a la distinción entre lo pasado y lo sido. Lo que aquí está nuevamente en cuestión es la caracterización más corriente de la historia, según la cual se comprende a lo histórico como aquello que, extendiéndose en el tiempo, ha ingresado irreversiblemente en el pasado. En este cuestionamiento se plantea también el problema de la relación de la historia con el tiempo e incluso se torna problemático el mismo concepto tradicional de tiempo. De acuerdo con la interpretación usual, la historia está en una relación especial y más estrecha con el tiempo que la naturaleza, pues se la determina pura y simplemente a través del tiempo. Esto sucede, por ejemplo, cuando se dice que «la historia es lo pasado». No ocurre lo mismo con la naturaleza: nunca se dice que ella es lo pasado, lo presente o lo futuro. De manera que aun en la más general y corriente determinación de la historia a través del tiempo, éste no constituye "sólo un marco [Rahmen] indiferente para el desarrollo del acontecer» $(G A 38,102)$. La destrucción ha mostrado que la orientación general de la comprensión usual de lo histórico-mundano, sea un ente o una acción humana, a partir de lo anterior, de lo que nos precedió, es en cierto modo fenoménicamente legítima, pero sólo si se comprende lo históricamente anterior no ya como lo pasado, sino como lo sido, como lo perteneciente a un mundo sido. Pero, ¿en qué sentido lo histórico-mundano es algo sido y no sólo algo pasado? ¿Cuál es la diferencia entre lo sido y lo pasado en cuanto determinaciones del tiempo?

Si consideramos un determinado acontecimiento histórico como, verbigracia, la Revolución francesa de 1789 , vemos que este acontecimiento ha pasado efectivamente, ha quedado atrás. Pero no puede decirse que haya pasado en sen- 
tido absoluto, en el sentido de que haya desaparecido por completo, de que se haya vuelto una nada. Prueba de ello es que la investigación historiográfica posterior ha interpretado unánimemente la Revolución francesa como un acontecimiento extraordinariamente relevante, que implica el paso de una época histórica a otra, de la Era moderna a la contemporánea, como un acontecimiento que ha determinado decisivamente la existencia del mundo occidental después de 1789. De manera que en la consideración de lo pasado, sea historiográfica o no, no sólo ni principalmente se tiene en cuenta el haberse hundido en el pasado del respectivo acontecimiento, sino también su haber sucedido y el modo y la significación de lo sucedido, en suma, el «haber llegado a ser» [Gewordensein] (GA $38,103)$. Pues en lo que ha llegado a ser, en lo que ha sido en un mundo, reside algo que pervive o repercute posteriormente de un modo más o menos determinante. De acuerdo con ello, Heidegger sostiene:

Lo pasado no es simplemente lo que desaparece [das Vergehende], sino lo que aún permanece, lo que repercute ulteriormente, lo que desde antes [von früher her] aún existe de algún modo, lo que desde antes aún es [west $]$ (...), lo que sigue siendo [das noch Wesende] o lo sido [das Gewesene]. Lo sido es por cierto siempre algo pasado, pero no todo lo pasado es algo sido en el sentido de lo que sigue siendo desde antes $(G A 38,103)$.

A diferencia de lo pasado en el sentido de lo que ha desaparecido, lo sido es aquello que "desde antes», es decir, a partir de una anterioridad en cuanto pertenencia a un mundo sido, permanece aún hoy, en el presente respectivo. Lo sido es aquello que aún existe [ist da] de algún modo, en la medida en que todavía «repercute» o determina en cierto modo el ser-en-el-mundo de un Dasein existente ${ }^{10}$. Heidegger distingue pues entre Vergangenheit, pasado, y Gewesenheit,

\footnotetext{
${ }^{10}$ En el texto citado anteriormente llama la atención la identificación en este contexto de das Gewesene, «lo sido», con das Wesende, que hemos traducido como «lo que sigue siendo». ¿Qué significa aquí la expresión das Wesende? En la formación del participio wesend, el sustantivo Wesen, "esencia», es utilizado, de un modo irregular, como verbo. En cuanto al contenido semántico del verbo wesen utilizado para la formación de dicho participio, Heidegger indica en Was heisst Denken?, Tübingen 1954, p. 143: «la palabra «wesen», usada verbalmente, es el alto alemán «wesan». Es la misma palabra que "währen» (durar) y significa: permanecer [bleiben]. Wesan pertenece a la raíz del índico antiguo vásati, es decir, habita, permanece». De acuerdo con ello, lo sido puede ser caracterizado con pleno derecho como das Wesende, «lo que sigue siendo», en la medida en que es aquello que, siendo anterior, aún dura, permanece.
} 
haber sido, como dos modos radicalmente distintos de comprender el carácter tempóreo de lo histórico-mundano en el sentido de lo anterior, de lo que nos precedió. No se trata sólo de una distinción terminológica, sino que la distinción se funda a su vez en dos maneras, en cierto modo contrapuestas, de comprender el tiempo:

Al pensar el pasado vemos en la dirección del irse del tiempo a partir del presente hacia el ámbito del pasar, del desaparecer. Con el haber sido miramos, al revés, desde lo sido hacia el presente. En el primer caso tomamos el tiempo como algo que, a partir del futuro pasando por el presente, se pierde en el pasado. En el otro caso tomamos el tiempo como algo que, a partir del pasado, pasando por el presente, avanza hacia el futuro $(G A 38,103)$.

Si bien en este texto se expresan correctamente las diversas perspectivas respecto del curso del tiempo que introduce la distinción entre pasado y haber sido, queda sin embargo en cierto modo encubierta, a causa de esta contraposición niveladora, la diferencia radical que introduce el concepto de haber sido en la comprensión del tiempo. En efecto, el tiempo es concebido, por un lado, en el sentido del tiempo físico como una dimensión o «marco indiferente», en el que está todo suceso, todo cambio, que llega a ser «histórico» en la medida en que ingresa en el «tiempo anterior», en el ahora que ya no es. Y, por otro lado, en la compresión de lo histórico-mundano como lo sido, el tiempo ya no es comprendido como una serie homogénea de puntos-ahora que fluye hacia el pasado, sino que, en principio, se muestra como aquello que se origina y brota a partir de lo histórico mismo. En lo histórico-mundano parecen confluir entonces ambas determinaciones del tiempo, pues es tanto lo pasado, lo que nos precedió, como lo sido, lo que aún permanece de algún modo. Por ello, el enigma del origen ontológico del carácter histórico de lo intramundano sólo podrá comenzar a develarse cuando logremos comprender cómo lo histórico-mundano, siendo algo pasado, puede convertirse a la vez en algo sido, en algo capaz de determinar también la existencia presente y futura del Dasein.

Otro aspecto importante de la destrucción de la «historia» desarrollado en GA 38 es el cuestionamiento de la orientación a partir de lo anterior, de lo que nos precedió, que caracteriza a la determinación usual de la historia. Hemos visto que esta orientación interpretativa es en cierto sentido fenoménicamente legítima. Pero a partir de la discusión hermenéutica de $G A 38$ se muestra a la vez 
como unilateral, pues también el futuro es relevante en la comprensión de la historia. En este sentido, sostiene Heidegger que «si un pueblo ahistórico entra en la historia, con "historia» no mentamos el pasado sino el futuro, que co-determina el pueblo que entra en la historia. Pero del mismo modo este pueblo puede ser expulsado de la historia; él está en cierto modo fuera (...) no tiene más futuro" $(G A 38,84)$. Así, la historia es comprendida inmediata y regularmente no sólo en relación con el pasado, con lo que nos precedió, sino también en relación con el futuro, con lo que vendrá. Pero en la cita precedente encontramos un concepto problemático, el de pueblo ahistórico, que debemos examinar antes de intentar comprender la conexión entre historia y futuro. Pues, ¿̨cómo puede hablar Heidegger de "pueblo ahistórico» después de que ha sostenido la tesis de que la historia es lo que distingue el ser del hombre?

Un pueblo ahistórico puede, según admite Heidegger, ingresar en la historia en la medida en que su existencia se convierte en determinante para el curso de los acontecimientos futuros. Es evidente que, en este contexto, Heidegger comprende la ahistoricidad en un sentido completamente distinto de la ahistoricidad que ha atribuido a lo inorgánico, a la "Tierra», y a la vida. Pues los entes no humanos son en sí mismos, en virtud de su modo de ser, ahistóricos y, por ello, no pueden por sí mismos ni entrar ni salir de la historia. En cambio, todo pueblo, en cuanto grupo o comunidad humana, es en sí mismo histórico, pues tiene el modo de ser del acontecer y, por ello, no sólo puede entrar por sí mismo en la historia sino que está siempre ya en la historia. De manera que un pueblo no puede ser ahistórico en el sentido de que, como lo inorgánico o lo meramente orgánico, no le es inherente el acontecer como modo de ser.

En $G A 38$ Heidegger introduce un concepto que permite comprender en su auténtico alcance la problemática expresión "pueblo ahistórico». Se trata de la noción de no-historia:

En todo acontecer existe aquello que produce ruido, estrépito, hay ostentación, habladuría, empresa, maquinación, emprendimiento, aparición de las casualidades, pasión de lo incontrolado, lo informe, los sucesos diariamente constatables. Todo esto pertenece a la historia tan necesariamente como el valle a la montaña. Y esto no es historia en sentido propio, sino nohistoria [Ungeschichte]. Esto no histórico tiene que ser nítidamente distin- 
guido de lo ahistórico. La vida vegetal y animal nunca puede ser no-histórica porque no conoce un acontecer como modo de ser $(G A 38,95)$.

$\mathrm{Si}$, como sugiere este texto, se reserva el término «ahistórico» para calificar a todo ente no humano, entonces la expresión «pueblo ahistórico» sólo puede significar en sentido estricto que dicho pueblo es no-histórico. En efecto, en cuanto grupo humano, un pueblo no-histórico pertenece siempre ya a la historia, puesto que le es propio el acontecer como su modo de ser. Sin embargo, está fuera de la "historia en sentido propio». Por ello, dicho pueblo tiene la posibilidad de entrar en la historia, es decir, en la historia en sentido propio, así como un pueblo propiamente histórico tiene siempre la posibilidad de llegar a ser no-histórico. Nos encontramos aquí con una distinción importante para nuestro tema: a la historia en sentido lato, es decir, a la existencia fáctica en cuanto acontecer, sea individual o colectiva, pertenecen las posibilidades de la no-historia y de la historia en sentido propio. «El acontecer como tal es no-histórico y al mismo tiempo también propiamente histórico» $(G A 38,99)$.

Pero, ¿qué y cómo es un pueblo no-histórico, un pueblo que aún no ha ingresado en la historia? Para responder a esta pregunta necesitamos en principio un concepto claro de historia en sentido propio, que aún no poseemos. A continuación procuraremos alcanzar un concepto claro de historicidad, a fin de comprender el modo como el futuro determina el ser histórico del Dasein y también el modo como en lo histórico-mundano pueden confluir ambas determinaciones del tiempo, el pasado y el haber sido.

\section{La resolución como modo propio de ser histórico}

Lo histórico-mundano es sólo secundariamente histórico, pues deriva su carácter histórico de su pertenencia a y procedencia de un mundo sido. Pero un mundo sido no es necesariamente un mundo pasado. El respectivo mundo presente, actual, es tan histórico como cualquier mundo pasado. Un mundo sido es aquel que pertenece a la estructura ontológica de un Dasein que ha existido. Por ello, el haber sido del Dasein es, desde el punto de vista ontológico, el fenómeno histórico primario y originario. Ahora bien, en cuanto fenómeno existencial, el haber sido no implica que el Dasein haya desaparecido, que haya muerto y que, por ende, pertenezca a un tiempo anterior. En cuan- 
to existencial, el haber sido es un modo de ser del Dasein existente. El Dasein es histórico mientras existe y cuando ya no existe, cuando ha muerto, es histórico porque ha existido, no porque ha desaparecido. Así llegamos a la extraña conclusión de que el Dasein ha sido mientras es, mientras existe. «En su ser fáctico, el Dasein es siempre como y «lo que» ya ha sido. Expresa o tácitamente, el es su pasado» $(S Z, 20)$.

Para superar la extrañeza de la anterior afirmación y comprender adecuadamente el ser histórico en el sentido del haber sido del Dasein, es necesario en primera instancia dirigir la mirada hacia el concepto existencial de facticidad. En sentido existencial, "facticidad» mienta el hecho de que el Dasein es y tiene que ser, es decir, tiene que responder en cada caso por la existencia a la que está entregado ${ }^{11}$. «Facticidad» significa que el Dasein está arrojado en la existencia en cuanto ser-en-el-mundo, lo cual implica que está siempre arrojado en un mundo y en determinadas posibilidades de existencia. Pero el Dasein encuentra las posibilidades, en las que en cada caso está arrojado, en su respectivo mundo circundante y compartido. En este sentido, Heidegger sostiene que todo mundo sido constituye un «legado» [Erbe] $(S Z, 383)$, es decir, un espacio abierto de significación que atesora un conjunto de posibilidades de existencia que han sido y que el Dasein, en cuanto arrojado, puede descubrir $y$, eventualmente, hacer suyas, heredar. La facticidad implica también que las posibilidades en las que el Dasein proyecta su existencia no son producidas libremente por él ex nibilo, como si la existencia flotase en el vacío y el Dasein fuese un sujeto sin mundo, sino que están dadas previamente para cada Dasein en el respectivo complejo significativo ya interpretado y transmitido. El Dasein es entonces histórico porque existe fácticamente, porque ha sido. Lo cual no significa que desde hace un tiempo pueda constatarse que está efectivamente presente en el «mundo», sino que, en cuanto arrojado en la existencia, el Dasein vuelve previa y constantemente hacia determinadas posibilidades legadas que encuentra en su mundo circundante y compartido y hacia sí mismo en cuanto ya arrojado en la existencia. En esta vuelta, en este retorno existentivo [existenziell] hacia lo transmitido, encontramos aquel tipo de movilidad que Heidegger ha atribuido exclusivamente al ser del Dasein y que ha denominado Geschehen, acontecer.

${ }^{11}$ Cf. $S Z \S 29$. 
El Dasein es siempre ya histórico en la medida en que, en cuanto fáctico, retorna a lo sido. Éste es ciertamente un concepto amplio de historicidad, formalmente neutro e indiferente respecto de la distinción entre propiedad e impropiedad de la existencia ${ }^{12}$. Sin embargo, hemos visto que Heidegger distingue expresamente entre no-historia e historia en sentido propio. Esto implica que la historicidad del Dasein puede asumir fácticamente las formas de la propiedad y la impropiedad. Ahora podemos comprender esta distinción a partir del concepto de historicidad examinado: lo que en principio distingue la historicidad propia de la impropia es el modo como el Dasein vuelve al legado de posibilidades mundanas del que se nutre toda existencia fáctica. La existencia cotidiana y cadente se caracteriza porque en ella «el sí-mismo está perdido en el uno» ( $S Z$, 383), esto es, porque el Dasein se comprende habitualmente a partir de las posibilidades mundanas bosquejadas por el uno en la convivencia pública ${ }^{13}$. El Dasein cadente toma simplemente las posibilidades en las que se proyecta del mundo ya interpretado donde está arrojado. Esto implica que el retorno existentivo hacia el legado de posibilidades mundanas se realiza habitualmente en la existencia cotidiana bajo la forma de una mera recepción. Pero la mera recepción no es el único modo de comportamiento posible respecto de lo legado en cuanto tal. Antes bien, Heidegger encuentra en el fenómeno existencial de la resolución o estar decidido [Entschlossenheit] un modo completamente distinto de acontecer, de retorno hacia lo sido:

La resolución, en la que el Dasein vuelve a sí mismo, abre las respectivas posibilidades fácticas del existir propio a partir del legado, que ella en cuanto arrojada asume. El retorno resuelto a la condición de arrojado encierra en sí un transmitirse [Sichüberliefern] posibilidades recibidas, aunque no necesariamente como recibidas [überkommen] $(S Z, 383)$.

Si bien todo Dasein, en cuanto arrojado, toma las posibilidades en las que se proyecta a partir del legado, a partir de su mundo circundante y compartido, sólo el Dasein resuelto asume esas posibilidades mundanas y no se limita simplemente a recibirlas. La recepción de posibilidades que han sido en la resolución se distingue porque constituye un transmitirse, una autotransmisión de las posi-

\footnotetext{
${ }^{12}$ Cf. $S Z \$ 9$.

${ }^{13}$ Cf. $S Z \$ \$ 27,38$.
} 
bilidades recibidas. "Autotransmisión» significa aquí que el Dasein asume o elige desde si mismo las posibilidades legadas en las que se proyecta. En la medida en que en la autotransmisión el Dasein ha elegido por sí mismo la posibilidad legada, en que se ha apropiado de ella, la resolución constituye el modo propio del acontecer, la historicidad propia. "Con la resolución estamos en el ámbito de la historia, no en algún ámbito cualquiera de hechos, sino en lo que llamamos historia en un sentido destacado» ( $G A 38,78)$. "La historicidad propia comprende la historia como el «retorno» de lo posible» $(S Z, 391)$.

Sin duda el Dasein no resuelto, cadente, se proyecta también en posibilidades recibidas a partir del mundo circundante y compartido, de tal manera que en cierto modo se transmite esas posibilidades. Pero en esta transmisión cadente no se lleva a cabo una mediación expresa, una autotransmisión en el sentido de una elección explícita de las posibilidades heredadas. El Dasein cadente tiende a comportarse respecto de lo transmitido de modo tal que no ve en ello posibilidades, susceptibles de ser elegidas o rechazadas, sino que, inmerso en los «sucesos diariamente constatables» $(G A 38,95)$, se atiene a los «hechos», a los contenidos del presente, y se limita a aceptar lo vigente o relevante en el respectivo mundo público. Este retorno a lo transmitido en el sentido de una mera recepción de lo vigente en el mundo público, de aquello que se le ha impuesto al Dasein o en lo que simplemente "ha crecido», constituye el modo impropio del acontecer, la historicidad impropia.

Con las expresiones Entschlossenheit o Entschiedenheit, Heidegger se refiere a un estado o carácter de ser del Dasein que surge a partir de una decisión [Entscheidung]. Ahora bien, decisiones hay muchas y de muy diverso tipo. Por ello, es preciso determinar aún qué clase de decisión considera Heidegger como un acontecer propio, qué tipo de decisión supone el ejercicio existentivo pleno del ser histórico del Dasein.

Una decisión es siempre una elección entre diversas posibilidades que se presentan como factibles. Pues sobre lo imposible, lo que no está a nuestro alcance, o sobre lo necesario, lo que no puede ser de otra manera, no se puede decidir. Al sentido pleno de una decisión pertenece también el que se presenten múltiples y diversas posibilidades elegibles: uno se decide en cada caso por esto y no por aquello, a favor de éste y en contra de aquél. En una decisión está también siempre de algún modo en juego el ser-sí-mismo del Dasein, su mismidad. Cuando 
la elección entre las distintas posibilidades se deja librada al azar o a las circunstancias, simplemente se evita la decisión. Pero detrás de la huida o de la renuncia expresa al ejercicio de la decisión hay sin embargo una elección: la de no decidirse, el querer no decidir. El recurrir al azar o al curso de las circunstancias para tomar una decisión, implica al menos la elección de no participar, de no involucrarse el Dasein a sí mismo en la decisión.

En cambio, el ejercicio de la decisión implica que el Dasein se decide, es decir, se involucra o compromete a sí mismo en algo, se pone a sí mismo en una posibilidad y no en otra. Un juez, por ejemplo, es aquel que tiene la responsabilidad de decidir acerca de la culpabilidad o inocencia de un acusado en el marco de un proceso judicial. El juez ejerce su decisión mediante la emisión de un fallo, cuya fundamentación no sólo contiene consideraciones legales de orden general, sino también su propia interpretación del hecho que juzga y su aplicación de la ley en el caso concreto. De manera que mediante el ejercicio de su decisión, el juez se compromete, se involucra necesariamente a sí mismo, y se convierte en si mismo, es juez. Antes de ejercer su decisión, el juez no era propiamente sí mismo en cuanto juez. Pues a pesar de que, por su jurisdicción, le hubiese tocado en suerte el caso en cuestión, el juez también podría haber evitado la decisión, argumentando, por ejemplo, la existencia de fallas formales en el proceso o declarándose «incompetente» por motivos personales. Es claro pues que existe una estrecha y peculiar conexión entre el ejercicio de la decisión y el más propio ser-sí-mismo del Dasein.

El grado de compromiso del sí-mismo que implican las diversas decisiones depende en buena medida del objeto o asunto sobre el cual recae la decisión. Si bien toda auténtica decisión supone un compromiso del sí-mismo, es evidente que existe una diferencia en el grado de compromiso entre la decisión de un juez, que debe decidir sobre la libertad o los bienes de una persona, y la del árbitro de una competencia deportiva, que debe decidir sobre la asignación de un premio a un competidor. Pero en GA 38 Heidegger sugiere además que, en cuanto al compromiso del sí-mismo, existe una diferencia de principio entre aquellas decisiones que recaen a favor o en contra de los otros o de algo otro y aquellas que recaen sobre sí mismo en el sentido de la determinación de la propia posibilidad de existencia ${ }^{14}$. ¿En qué se funda esta diferencia de principio entre ambos tipos de decisión?

\footnotetext{
${ }^{14}$ Cf. $G A 38 \$ 15$ a y b.
} 
Cuando alguien se decide por algo, por ejemplo, cuando el juez se decide por la inocencia del acusado o el árbitro por la asignación del premio al competidor A, la decisión termina con la realización de la decisión. El acto de la decisión lleva a término el asunto de que se trata. En cambio, cuando el Dasein decide acerca de sí mismo en el sentido de que elige proyectarse en una determinada posibilidad de existencia, la decisión no se limita al acto de la decisión. En este caso, la decisión no llega a su momento final cuando se toma, sino que comienza sólo entonces y perdura: la decisión se convierte en un estar decidido o resuelto. La perdurabilidad o constancia que es inherente al estar resuelto a proyectarse en una posibilidad de existencia es un momento esencial del tipo de decisión que está en juego en el fenómeno de la resolución. En cambio, en aquellas decisiones que no implican un compromiso constante, el Dasein no ha alcanzado aún la Entschlossenheit, el estado de resuelto. Por ejemplo, el caso de un fumador que ha decidido dejar de fumar, pero quiere comenzar recién la próxima semana. Este fumador está decidido, pero no resuelto. Pues así como ha aplazado la realización efectiva de su decisión, puede posteriormente también fumar «en una ocasión especial», es decir, suspender momentáneamente su decisión y tener que repetir la decisión, lo que demuestra que aún no está resuelto. La resolución no admite este tipo de comportamiento oscilante. En ella, el compromiso del sí-mismo es completo, pues la decisión recae en el propio ser del Dasein en cuanto poder-ser. Cuando se resuelve a proyectarse constantemente en una posibilidad, el Dasein llega a ser propiamente sí mismo. «Estamos resueltos a algo - esto implica que aquello respecto de lo cual estamos resueltos, está constantemente ante nosotros, determina todo nuestro ser. Ello nos ocupa no ocasionalmente, sino que la resolución da a nuestro ser una impronta y constancia completamente determinada» $(G A 38,77)$.

A partir del concepto de resolución como un firme y constante estar decidido del Dasein a proyectarse en una posibilidad de existencia, podemos volver ahora hacia la cuestión planteada anteriormente acerca de la conexión fenoménica entre historicidad y futuro. Al respecto, Heidegger señala que «en la resolución el hombre es introducido en el acontecer futuro. La resolución es en sí misma un acontecimiento [Geschehnis] que, anticipando aquel acontecer, co-determina el acontecer» $(G A 38,77)$. La noción de resolución no se refiere pues a una cualidad subjetiva, la de ser un hombre decidido, sino que busca destacar un acontecimiento primordial, no en el sentido usual de un suceso óntico, intramundano, sino en el sentido ontológico-existencial de un modo destacado de ejercicio de la existencia. En la medida en que el acontecimiento de la resolución impli- 
ca la decisión inaugural de proyectarse de un modo perdurable en una posibilidad, el Dasein es introducido, a través de la resolución, en el futuro de su propio ser-posible. El estar resuelto a algo abre el futuro del Dasein, pues anticipa el «acontecer futuro», el ejercicio venidero de la existencia.

La resolución, en el sentido de ese acontecimiento que abre el futuro del Dasein, constituye ciertamente un acontecer propio y, por ende, forma parte del concepto existencial de historicidad propia. En GA 38 Heidegger se refiere a este aspecto del concepto de historicidad propia tomando como referencia la existencia histórica colectiva, la historia de los pueblos. Allí se pregunta básicamente qué significa, desde un punto de vista existencial, la experiencia de que, bajo determinadas condiciones, un pueblo «entra en la historia». Esto no puede significar el posible tránsito desde la existencia ahistórica a la histórica, pues, como hemos visto, la existencia es histórica per se. La entrada de un pueblo en la historia implica un acontecimiento primordial: el ingreso de su existencia colectiva en la historicidad propia. De acuerdo con ello, un pueblo, una comunidad, es histórica en sentido propio no simplemente cuando en su seno pueden constatarse cambios, luchas, acontecimientos «relevantes», personajes dominantes, etc., sino sólo cuando se resuelve, cuando es capaz de determinar desde sí misma, con firmeza y constancia, aquellas posibilidades esenciales en las que proyecta su existencia colectiva.

Los pueblos no ingresan en la historia como si ésta fuera un espacio preexistente en el que encuentran morada, una vía ya existente que ellos sólo tendrían que recorrer, sino que «hacer historia» significa: crear el espacio y el suelo. «Hacer» no significa aquí producir en el sentido en que se puede producir y conservar una cosa. Aún cuando un pueblo hace su historia, esta historia no es lo hecho por el pueblo; el pueblo se hace a través de su historia $(G A$ $38,84-85)$.

A lo largo de nuestro examen del concepto de resolución como modo propio de ser histórico, nos hemos encontrado con dos nociones distintas y aparentemente contrapuestas. Pues, por un lado, la resolución se mostró como un modo destacado de retorno existentivo hacia lo sido, retorno que consiste básicamente en una autotransmisión de posibilidades de existencia legadas, recibidas a partir del respectivo mundo circundante y compartido. Y, por otro lado, la resolución se mostró como un modo destacado de decisión, en el sentido de un firme y constante estar decidido a proyectarse en determinadas posibilidades, a través 
del cual el Dasein es introducido en el futuro de su propio ser-posible. El fenómeno de la resolución aparece entonces como un peculiar acontecer, al que es inherente un movimiento existencial de doble sentido, pues es tanto un estar vuelto del Dasein hacia lo sido, cuanto un estar vuelto hacia el futuro, hacia lo venidero. Cabe entonces preguntar si acaso pueden conjugarse de algún modo ambas determinaciones, de manera que la resolución se muestre como un fenómeno unitario.

En cuanto acontecer, la resolución implica una vuelta del Dasein hacia lo sido dentro de un mundo. Hemos visto que Heidegger distingue entre lo pasado y lo sido como dos modos distintos de comprender el carácter tempóreo de lo histórico-mundano. Lo pasado es lo que nos precedió, lo que pertenece a un tiempo anterior $y$, por ende, ha quedado irremediablemente atrás, ha desaparecido. También lo sido pertenece a un tiempo anterior, pero, a diferencia de lo meramente pasado, lo sido aún permanece, en el sentido de que puede repercutir ulteriormente, de que puede ser retomado de algún modo. Ahora bien, lo sido no es simplemente aquello respecto de lo que puede constatarse que repercute hoy, aquello que tiene todavía algún grado de eficacia sobre el presente respectivo. Pues las repercusiones del pasado en el presente, múltiples y muy diversas, dependen siempre de lo que se considera como vigente en el mundo público actual. En cuanto rasgo ontológico primario de lo histórico-mundano, lo sido no es para Heidegger simplemente lo que aún hoy repercute. Lo sido es tanto lo que sigue siendo [das Wesende] como lo esencial: "Lo esencial [das Wesentliche] no puede ser determinado a partir de lo eficaz [das Wirksam]» (GA 38, 116). Pero, ¿cómo y quién puede determinar qué es lo históricamente esencial? Si el carácter histórico de lo intramundano se funda en la historicidad del Dasein, entonces lo sido, en el sentido de lo histórico-mundanamente esencial, no puede determinarse a partir de lo que se considera como relevante o vigente en el respectivo mundo público, sino a partir del ejercicio propio del ser histórico por parte del Dasein resuelto.

Lo esencial lo experimentamos sólo a partir del cómo y del para qué de nuestra autodecisión, la que nosotros queremos hacer venidera, la que nosotros queremos poner bajo nuestro mando como nuestro porvenir. Lo que sigue siendo desde antaño se determina a partir de nuestro futuro $(G A 38,117)$.

Lo histórico-mundano tiene carácter de sido. Pero lo sido no es sólo aquello que, procediendo de un tiempo anterior, tiene algún grado de repercusión, más 
o menos constatable, en el juego de intereses del mundo actual. Lo sido es ante todo aquello que, como parte del legado de un mundo fáctico, se convierte en esencial, en existencialmente determinante, en la medida en que es descubierto y expresamente heredado por un Dasein que está resuelto a proyectarse en una posibilidad legada y ha abierto así anticipadamente su propia existencia futura. Esto nos permite comprender la unidad del fenómeno de la resolución, que se funda en la unidad del ser del Dasein en cuanto proyecto arrojado. ${ }^{15}$ En efecto, en su carácter de proyecto, la resolución consiste en un estar decidido a proyectarse en una posibilidad de existencia. Pero esta posibilidad no surge de la nada, no es el resultado de la imaginación, de la invención o del capricho. Antes bien, el Dasein resuelto da en cada caso con esta posibilidad en la medida en que, en cuanto arrojado, retorna a lo sido dentro de un mundo, a partir del cual le sale al encuentro la respectiva posibilidad legada que él asume.

El futuro no viene a nosotros por sí mismo, sino sólo si somos capaces de seguir la tradición, de asumirla, en vez de perdernos en empresas actuales y de desperdiciarnos. Nuestro haber sido y nuestro futuro no tienen el carácter de dos espacios de tiempo, de los cuales uno ya ha pasado y el otro aún debe ser ocupado, sino que lo sigue siendo desde antaño es en cuanto futuro de nuestro propio ser $(G A 38,118)$.

\section{Conclusión: Lo histórico-mundano como huella y testimonio}

A partir de esta comprensión integral del fenómeno de la resolución como un acontecer que abre co-originariamente lo sido y el futuro del Dasein, podemos volver ahora al problema planteado al comienzo acerca del origen ontológico de lo histórico-mundano. En el marco de la destrucción de la interpretación usual de la historia, se ha mostrado que el carácter histórico de lo intramundano no se debe exclusiva ni primariamente a su pertenencia a un tiempo pasado, sino que se funda ontológicamente en su procedencia de un mundo sido. Esta tesis implica que, en cuanto estructura ontológica, el carácter histórico no consiste propiamente en ser algo pasado sino en ser algo sido, es decir, algo que perdura, que siempre puede ser retomado de algún modo por un Dasein existente. El análisis de la resolución puso además de relieve que lo sido no es

\footnotetext{
${ }^{15}$ Cf. $S Z \$ 41$.
} 
simplemente lo que tiene algún grado de repercusión en el mundo actual, sino que la fuerza de su permanencia radica en el hecho de que es capaz de determinar de un modo decisivo la existencia de un Dasein resuelto, es decir, de posibilitar una existencia propiamente histórica.

Ahora bien, como destacamos anteriormente, en la interpretación heideggeriana ha quedado sin aclarar cómo puede lo histórico-mundano, siendo algo pasado, convertirse en algo sido, cómo puede presentarse posteriormente como algo relevante para la existencia del Dasein, cómo puede conservar su fuerza existencial. Es necesario aún determinar qué es propiamente lo que, en la estructura ontológica de lo intramundano, hace posible su procedencia de un mundo, que funda su carácter histórico. Para responder a estas preguntas no basta con apelar, como hace Heidegger, al «acontecer intramundano» del ente o de los acontecimientos humanos, a su ingreso en el mundo como consecuencia de su originario descubrimiento por parte del Dasein, pues esto no explica por qué lo que en un tiempo anterior ha llegado a ser intramundano puede convertirse en algo capaz de determinar decisivamente la existencia del Dasein en un tiempo posterior. Y tampoco es suficiente decir, con Figal, que lo pasado se convierte en histórico-mundano porque se transmiten los correspondientes enunciados históricos acerca de ello, pues los enunciados históricos se refieren en cada caso a lo pasado en cuanto histórico-mundano, es decir, sólo hacen expreso algo que ya es inherente a la estructura ontológica de lo histórico-mundano.

El examen del fenómeno de la resolución como modo de ser histórico nos permite ensayar una respuesta a las preguntas planteadas. Lo intramundano en sentido amplio adquiere carácter histórico, en el sentido ontológico-tempóreo de carácter de sido, y, por ende, llega a ser histórico-mundano, en la medida en que se muestra dentro del mundo como vestigio de una posibilidad de existencia. En efecto, los restos encontrados, las antigüedades conservadas, los sucesos ocurridos y los acontecimientos humanos pasados, de los que poseemos relatos orales o testimonios escritos, son histórico-mundanos no simplemente porque pertenecen a un tiempo anterior, al pasado, sino principalmente porque se presentan dentro del mundo como signos que hacen accesible, circunspectiva o teoréticamente, el poder-ser-en-el-mundo de un Dasein que ha existido.

Nuestra interpretación puede ser aclarada y fenomenológicamente fundamentada si tomamos como punto de partida la comprensión heideggeriana de 
la estructura intencional de los comportamientos. De acuerdo con ella, a todo comportamiento del Dasein respecto del ente es inherente una correlación entre el sentido de contenido, lo que se experimenta, y el sentido de referencia, el modo como se experimenta el contenido significativo. ${ }^{16}$ En cuanto contenido significativo, el carácter histórico es una estructura ontológica: un (posible) carácter de ser del ente intramundano. Esto implica que el carácter histórico no consiste en un qué, en un contenido óntico determinado, en una propiedad constatable del respectivo ente, sino en un cómo, en un modo de estar desoculto o descubierto del ente. El modo de estar desoculto de lo histórico-mundano, su carácter de sido, constituye el correlato fenoménico de un modo determinado de comportamiento intencional: el ser histórico del Dasein en cuanto retorno existentivo hacia lo legado dentro de un mundo, que contiene siempre una comprensión del ser. En efecto, si el ser histórico del Dasein consiste en un previo y constante retorno hacia posibilidades legadas que descubre en su mundo circundante y compartido, el correlativo carácter histórico de lo intramundano es un modo de estar descubierto, que consiste en ser un vestigio, un Rückzeichen, es decir, un signo que retrotrae hacia una posibilidad legada que retorna. Esta posibilidad no se muestra en sí misma, pues pertenece a un Dasein que ha existido, sino que se muestra bajo la forma de un vestigio accesible en lo intramundano. «En el vestigio [Rückzeichen] se hace circunspectivamente accesible lo ocurrido, lo que ha tenido lugar» (SZ, 80).

Usamos aquí la palabra "vestigio», lat. vestigium, en un sentido cercano al habitual de pisada, rastro o «huella que deja en la tierra el pie del hombre o animal que pasa» y de «memoria o noticia de las acciones de los antiguos que se observa para la imitación y el ejemplo» ${ }^{17}$. En nuestro sentido, «vestigio» mienta también una huella o rastro que deja el Dasein de una posibilidad de existencia, no sólo en "la tierra» sino en todo tipo de ente que el Dasein haya "hollado» o producido de alguna manera y hecho ingresar en un mundo. Asimismo, «vestigio» nombra la «noticia» o el testimonio que un Dasein ha dejado de sí mismo en un ente intramundano (restos, ruinas, antigüedades, monumentos, relatos

${ }^{16}$ Para la concepción heideggeriana de la estructura intencional de los comportamientos, véase especialmente las lecciones Phänomenologie des religiösen Lebens. 1. Einleitung in die Phänomenologie der Religión (1920/21) y Phänomenologische Interpretationen zu Aristóteles (1921/22). Para un excelente análisis introductorio de este tema, véase Ramón Rodríguez (1997), pp. 36-70.

${ }_{17}$ Diccionario de la Lengua Española (1992), p. 1477. 
orales o documentos escritos, etc.) y que siempre puede ser, si no ya «imitado» o considerado como «ejemplo», al menos comprendido y proyectado nuevamente de alguna manera por el Dasein en un tiempo posterior. Lo que en cuanto sido, y no simplemente como pasado, es capaz de determinar, en la resolución, el poderser venidero de un Dasein existente, es entonces el vestigio de una posibilidad de existencia, inherente a la estructura ontológica de lo histórico-mundano.

Heidegger acierta cuando señala que el carácter histórico de lo intramundano se origina en su procedencia de un mundo sido. Pero a continuación es necesario añadir que esa procedencia sólo puede ser reconocida si se descubre en lo intramundano una notificación o registro de la posibilidad de existencia por mor de la cual fue descubierto o producido originariamente dentro de un mundo. Mediante esta notificación, que naturalmente tiene lugar de maneras muy diversas, lo intramundano se convierte en huella. La notificación primaria, la huella, inaugura a su vez para lo intramundano la posibilidad de convertirse en testimonio de la existencia que ha sido. Pero lo intramundano sólo llega a convertirse en testimonio mediante la transmisión, es decir, mediante el ejercicio del ser histórico por parte de un Dasein existente. Si el registro de la posibilidad en lo intramundano es una notificación primaria, la posterior autotransmisión de dicha posibilidad por parte de un Dasein existente tiene el carácter de una notificación secundaria. Desde esta perspectiva, la transmisión de enunciados datados, sea a través del relato oral, el testimonio escrito, la novela histórica, la arqueología o la historiografía, tiene que ser considerada como una forma de notificación secundaria, tal vez la más relevante, que hace verbalmente expresa y ulteriormente comunicable la notificación primaria, acaso muda o enmudecida, de una posibilidad en lo intramundano.

Desde el punto de vista de su sentido de contenido, lo histórico-mundano tiene el carácter de lo transmitido, es decir, de aquello que, procediendo de un tiempo anterior, muestra en el presente respectivo la huella y el testimonio de una posibilidad de existencia. En este sentido, lo histórico-mundano se distingue de lo no hollado por el hombre, de la naturaleza meramente conservada, que, si bien procede de un tiempo pasado y también se muestra en el presente, no puede ser sin embargo el testimonio de ninguna posibilidad, pues no ha sido originariamente notificada por el Dasein.

El Dasein sólo puede acceder a una posibilidad que ha sido a través de un testimonio transmitido en lo histórico-mundano. Pero lo transmitido no garan- 
tiza por sí mismo que lo que se muestra inmediatamente sea un testimonio fiel de la posibilidad. Por el contrario, los contenidos significativos transmitidos a través de las sucesivas generaciones, que conforman el respectivo estado de interpretado de un mundo público, están constantemente expuestos al peligro de la tergiversación, del encubrimiento. Esto se debe a que el proceso de transmisión, y particularmente el que se lleva a cabo a través de la comunicación lingüística, no busca regularmente mantener una relación originaria con lo que transmite, sino que, antes bien, tiende a desfigurarlo. Heidegger llega así a una posición ambivalente con respecto al fenómeno de la transmisión de lo sido o tradición [Überlieferung]. Pues, por un lado, considera que la tradición, en el sentido de lo histórico-mundanamente transmitido, es aquello que permite al Dasein ejercer propiamente su historicidad, la cual consiste tanto en una autotransmisión o apropiación originaria de lo sido cuanto en una proyección resuelta de la existencia, que abre el futuro a partir de lo sido. «Esta tradición no es ninguna existencia [Bestand] de conocimientos e informes, sino el carácter más interno de nuestra historicidad. A través de ella cargamos con nuestra propia determinación, somos entregados al futuro» (GA38, 117-118).

Y, por otro lado, Heidegger alerta sobre el peligro que la tradición, en el sentido de la transmisión encubridora de lo sido, puede suponer para el ejercicio de la historicidad del Dasein. Pues en la medida en que desfigura lo transmitido y presenta en el mundo público un contenido significativo históricamente desarraigado, la tradición impide un retorno originario a la posibilidad que ha sido y, al mismo tiempo, regula y dirige la autocomprensión y las posibilidades de decisión del Dasein. «El Dasein no sólo tiene la propensión a caer en su mundo (...) y a interpretarse reflejamente [reluzent] a partir de él, el Dasein cae a la vez con ello también en su tradición, más o menos expresamente asumida. Ésta le substrae la dirección de sí mismo, el preguntar y el elegir» $(S Z, 21)$. Puesto que la tradición puede obstruir el acceso del Dasein a sus propias raíces históricas, un auténtico retorno a lo sido, el ejercicio resuelto de la historicidad, implica la necesidad de superar la mera recepción inmediata de lo transmitido mediante una autotransmisión critica de lo sido, que penetre a través de los encubrimientos tradicionales. Desde esta perspectiva, la destrucción de las interpretaciones usuales, en cuanto momento metódico de la fenomenología hermenéutica, constituye el ejercicio de un tipo, teóricamente relevante, de comportamiento histórico propio. 


\section{Bibliografía}

Diccionario de la Lengua Española (1992), 21 a ed., Madrid.

FIgAL, G. (2000). Martin Heidegger. Phänomenologie der Freiheit, $3^{\mathrm{a}}$ ed., Weinheim.

Heidegger, M., GA 38: Logik als die Frage nach dem Wesen der Sprache (1934), ed. G. Seubold, Frankfurt a. M. 1998.

- Phänomenologie des religiösen Lebens. 1. Einleitung in die Phänomenologie der Religion (1920/21). GA 60, eds. M. Jung y Th. Regehly, Frankfurt a. M. 1995.

- Phänomenologische Interpretationen zu Aristóteles (1921/22), GA 61, 2a ed., eds. W. Bröcker y K. Bröcker-Oltmanns, Frankfurt a M. 1994.

- SZ: Sein und Zeit, 17a ed., Tübingen, 1993.

- Was heisst Denken?, Tübingen, 1954.

RODRÍGuez, R. (1997). La transformación hermenéutica de la fenomenología. Una interpretación de la obra temprana de Heidegger, Madrid.

Safranski, R. (1994). Ein Meister aus Deutschland. Martin Heidegger und seine Zeit, München/Wien.

Recibido: 21/02/2011

Aceptado: 1/04/2011 